\title{
Research on the Innovative Talents Training Mode of Civil Engineering Specialty Based on CDIO Concept
}

\author{
Jiangping $\mathrm{Ma}$ \\ Xi'an Peihua University, Xi'an 710125, China \\ 155045132@qq.com
}

\begin{abstract}
Expound the current society's urgent demand for talents with innovative ability and practical ability; Analyze the advantages of CDIO education mode on the cultivation of innovative talents; The investigation found that the current situation of training innovative talents in civil engineering specialty is as follows: the training objectives of innovative talents are unclear, innovative courses are not set properly, and the innovative ability of teachers is not strong. This paper puts forward an innovative talent training mode for civil engineering specialty based on CDIO education mode from four aspects: talent training target orientation, talent training mode reform, curriculum system adjustment and faculty strengthening.
\end{abstract}

Keywords: CDIO; Innovative talents; Personnel training; Teaching mode.

\section{基于CDIO理念的创新型土木工程专业人才培养模式研究}

\author{
马江萍 \\ 西安培华学院, 西安 中国
}

摘 要: 阐述当前社会对具有创新能力与实践能力人才的迫切需求; 分析CDI0教育模式对创新 人才培养的优势; 调研发现土木工程专业创新型人才培养的现状: 创新型人才培养目标不清、 创新性课程设置不当、师资队伍创新能力不强; 提出从人才培养目标定位、人才培养模式改 革、课程体系调整及师资队伍加强四方面着手基于CDIO教育模式的土木工程专业创新型人才 培养模式.

关键词 : CDIO ; 创新型人才 ; 人才培养 ; 教学模式.

\section{1. 前言}

在经济全球化的浪潮席卷之下，伴随着各国合作与竞争的日趋激烈，专业技术人才之间的竞 争也更加残酷。随着经济形势的变革, 社会需求也将有翻天覆地的变化, 同时行业需求、企 业需求以及职业需求都将随之变化, 为了适应全球化经济和社会发展大环境、适应当前的社 会时代潮流与趋势 [1]，人才的培养必须要转换结构与方式。

培养创新能力与实践能力并举的高素质工程技术人才是高校人才培养的主要目标与核心任务, 但在当前我国高校工程人才的培养却面临巨大的挑战: 强调理论忽视实践、培养具有创新实 践人才困难重重 $[2]$, 改革现行专业人才培养模式, 提出适合创新型人才培养的新方案是目前 高校人才培养发展的重要任务。

\section{CDIO教育模式}

根据国家颁布的2010-2020年长期教育改革和发展规划纲要, 我国高等教育需要将创新型人才 培养作为教育改革与发展的重要内容。基础知识扎实、个人能力突出、团队协作默契和创新 能力强的卓越工程人才是我国在科技革命和产业变革下创新型人才培养的目标。

CDI0 教育模式最早由麻省理工学院等四所大学联合研究创立 [2], 是一种让学生在产品或系 统从构思到运行的全生命周期中始终保持主动的、创造的、实践的学习状态的新型工程教育 
模式, CDI0 教育模式强调以工程实际项目为载体, 以工程人才培养中实践能力的提高、团队 协作能力的加强、创新能力的训练为宗旨，与创新型人才培养的目标相一致。

将创新型人才培养目标与 CDI0 教育理念进行综合融入土木工程专业人才培养理念之中, 通 过合理定位人才培养目标、构建课程体系、加强师资队伍建设, 是创新型土木工程人才培养 模式建设的有效途径之一。

\section{3. 土木工程专业创新性人才培养的现状}

笔者为深入了解土木工程专业人才培养的当前具体情况, 对陕西地区六所土建类高校（两所 重点院校, 四所新建本科院校) 的土木工程专业人才培养方案进行调研分析之后, 对比发现 培养目标与课程设置存在部分的不合理; 前期在陕西省高等教育学会基金支持下参与课题《新 工科背景下新建本科院校师资队伍建设研究》，经过对陕西1337名教师 (专任教师780名, 兼 职教师537名）其中土建类专业教师126名进行问卷调研, 发现师资队伍的建设也存在一些不 当:

\section{1. 创新型人才培养目标不清}

人才培养目标是高等院校对人才培养的宏观定位, 对课程体系的设置起着决定性的指挥作用。 在调查的六所土建院校中, 部分新建本科院校不能根据自身的实际情况进行创新型人才培养 的目标定位, 照搬照抄其他院校的人才培养方案, 提出不切合实际的培养目标与培养标准 (如 部分新建本科院校提出培养具有国际视野的、创新能力的高级技术和管理人才）。

\section{2. 创新性课程设置不当}

所调研的六所土建专业院校: 部分院校仍以传统教育模式为主, 强调理论教学对学生的知识 输入, 对创新型技能的培养不够重视; 部分新建本科院校认为对学生开设《创新创业》课程 就是对学生创新能力的培养, 理解比较片面; 还有部分院校创新实践课时不足教学计划总课 时的30\%, 创新训练环节较薄弱; 对于开设实践训练课程的院校也多以基础实践教学为主, 单 一的课堂教学演示、验证性实验教学对于创新意识、创新思维和创新能力的培养远远不够。

\section{3. 师资队伍创新能力不强}

通过对126名土建类教师的问卷分析，得知有66名年龄集中在 35 岁以下的教师是从高校毕业后 直接参加教学工作, 这部分教师作为创新能力培养的主要师资力量存在一个显著的问题: 缺 乏工程实践经验, 不能将理论与实践进行结合达到创新的要求; 21名年龄大于50岁的教师是 从重点大学退休的教授, 这部分教师理论知识扎实, 实践经验丰富, 属于学生创新能力培养 的坚实力量, 也存在一个明显的问题: 不能紧跟时代的步伐利用先进的设备进行开放式的学 生创新能力培养。

\section{4. 土木工程专业创新性人才培养的构建}

\section{1. 人才培养目标定位}

新建本科院校土木工程专业应根据自身的实际情况结合 CDIO 教育理念的需求, 在实施 “学生 为主体, 教学合一” 的教学改革中, 注重与建筑行业企业的共同发展、注重学生综合能力的 全面发展、注重学生自主学习意识的加强; 培养学生掌握土木工程基础知识, 基本原理、基 本方法, 加强外语和计算机训练的同时突出实践能力与创新意识, 以培养能从事工程设计、 施工与管理工作的土建人才为己任。 


\section{2. 人才培养模式改革}

基于 CDI0 教育模式, 在教学中以真实项目为教学背景, 在工程实施活动中, 实现学生由构思 到设计、实施并运行的自主学习, 以达到创新型人才的培养。

大一的学生以专业基础课程学习为主, 在课程比赛 (如土木工程制图比赛、测量比赛) 中加 强学生专业能力的培养、团队协作的配合, 同时图纸的识读也达到让学生体会土建工程师对 建筑施工图构思的目的; 大二的学生以专业核心课程学习为主, 课堂中真实项目的案例计算 加强学生专业化技能学习, 课下的自主课程设计不仅拓宽学生的知识面, 也让学生在项目中 实现建筑施工图到建筑结构图的设计转变; 大三的学生以专业方向课程学习为主, 根据行业 需求结合自身兴趣, 通过在真实项目中的实习实践, 达到专业应用能力的培养, 促进学生在 理论知识与实操能力并重的情况之下达到工程项目设计、施工的实施; 大四的学生以综合能 力训练为主, 通过顶岗实习、毕业实习与毕业设计的三重实践教学的磨练, 培养学生融入职 场环境、适应职场要求的综合能力，达到综合素质的全面提高。

\section{3. 课程体系调整}

为实现学生综合素质的培养, 达到创新型人才培养的需求, 构建 $\mathrm{CDIO}$ 一体化课程体系见图 1:

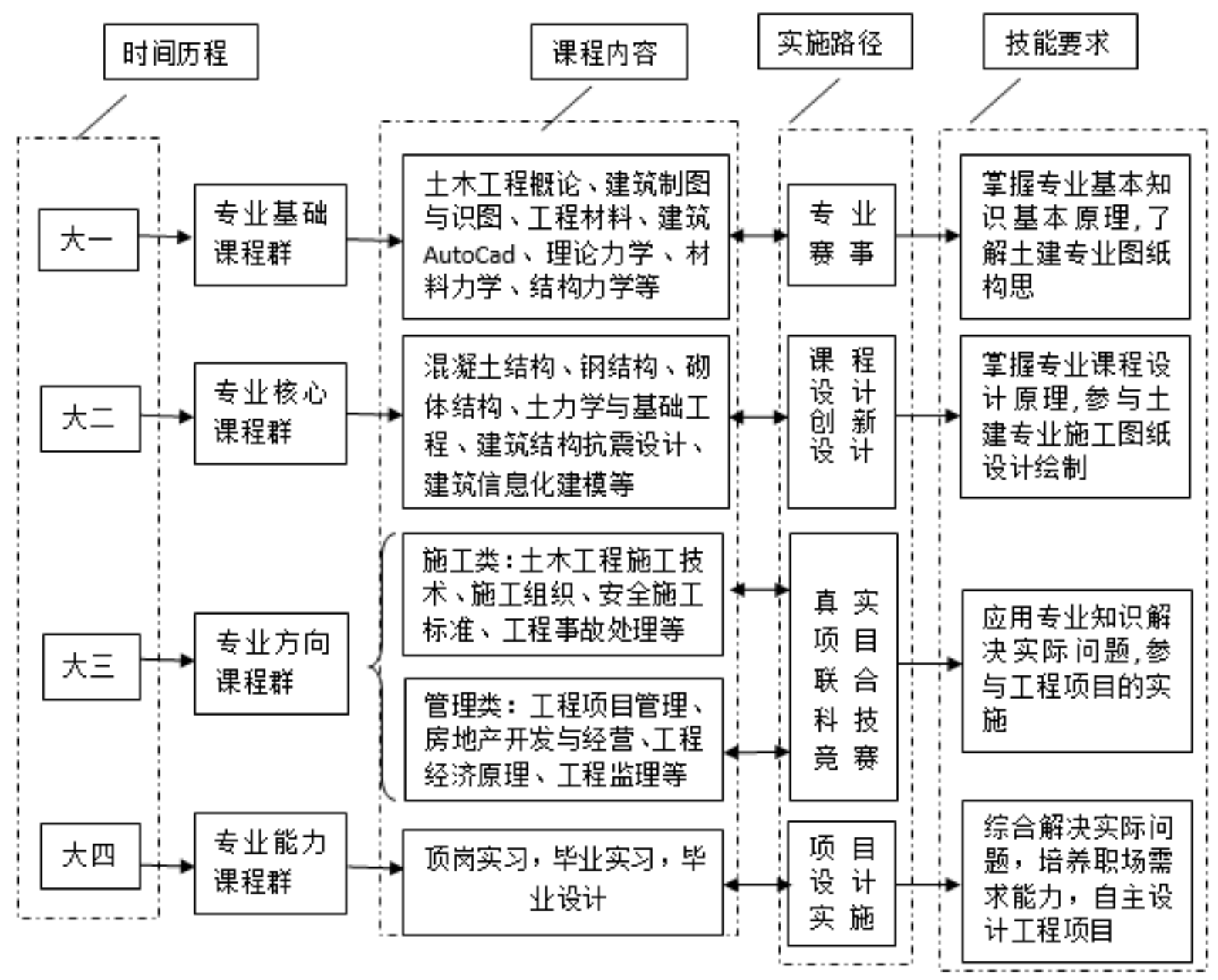

图1. 基于CDIO的土木工程课程体系 


\section{4. 师资队伍加强}

安排主要创新能力培养的师资队伍（青年骨干教师）, 定期参加行业研讨会、去企业参观调 研以及鼓励青年教师参与土建专业的项目设计，掌握最新的行业动态，拓宽专业创新视野; 为德高望重的年长教授在专业授课中安排助理教师, 青年教师为教授们的开放式创新教学提 供技术支持，同时教授们对青年教师实现专业帮扶，达到传帮带的效果。

\section{5. 结论}

土木工程专业作为一个专业知识复杂且与实践联系密切的专业, 在创新型人才的培养过程中, 首先需要理解 CDI0 教育模式的内涵, 结合学科特点将专业教学进行分类, 其次在准确定位 人才培养目标之后, 确定适合自身的人才培养模式, 将 CDIO 教育模式融入课程体系之中, 从 而实现创新型人才培养模式的改革。

\section{致谢}

感谢陕西省教育科学 “十三五” 规划基金, 本论文是课题 《基于 CIPP-CDI0 理念的创新型土 建人才培养模式研究》（SGH18H503）成果之一。

\section{References}

[1]. Wei Hairui. Exploration of experimental teaching reform for industrial engineering specialty based on CDIO education mode [J]. Journal of Higher Education, 2019,19:130-132.

[2]. Qi Lixia. CDIO-based Industrial Engineering Comprehensive Training Innovation Model Research [J]. Education Modernization, 2017 (35): 22-24.

[3]. Xue Yongbing, Zhao Organ, Liu Zhenmin. Construction of Practical Teaching System for Application-oriented Undergraduate Universities Based on CDIO Education Concept-Practical Teaching Research to Stimulate Innovative Motivation of College Students [J]. University Education, 2019,10:176-179.

[4]. Zha Jianzhong, Xu Wensheng, Gu Xueyong, et al. CDIO Model from Ability Syllabus to Integrated Curriculum System Design-One of Series Reports on Innovative Education Experimental Zone of Beijing Jiaotong University [J]. Research on Higher Engineering Education, 2013 (02): 10-23. 